\title{
Crónica de la Jurisprudencia del Tribunal de Justicia de la Unión Europea
}

\author{
David Ordóñez Solís \\ Magistrado y miembro de la Red de Expertos en Derecho \\ de la Unión Europea del Consejo General del Poder Judicial
}

\begin{abstract}
Sumario: I. Introducción. - II. Los Tribunales Constitucionales también aplican el Derecho de la Unión (y plantean cuestiones prejudiciales). 1. El Bundesverfassungsgericht acude al Tribunal de Justicia: asunto Gauweiler y otros (C-62/14). 2. La actitud del Tribunal Constitucional español después de la sentencia Melloni.-III. La nueva jurisprudencia europea sobre internet: sentencias Digital Rights Ireland, Google Spain y otras. 1. La anulación de la Directiva sobre conservación de datos: sentencia Digital Rights Ireland. 2. El derecho al olvido como manifestación de la Directiva 95/46: sentencia Google Spain. 3. Otras sentencias sobre Internet: competencia judicial y lucha contra la ciberpiratería. - IV. Los efectos de la Jurisprudencia Europea en el Derecho Español: Las Sentencias sobre el «céntimo sanitario» y la nueva multa por no recuperar ayudas ilegales. 1. La sentencia Transportes Jordi Besora (céntimo sanitario). 2. Las respuestas a otras cuestiones prejudiciales españolas. 3 . La sentencia de multa por las vacaciones fiscales vascas (C-184/11) 4. Las nuevas cuestiones prejudiciales españolas. - V. Relación de las sentencias comentadas del Tribunal de Justicia de la Unión Europea.
\end{abstract}

\section{Introducción}

Interrumpida la crónica semestral por el anterior número extraordinario de Cuadernos de Derecho Europeo en el que hice balance de 25 años de la jurisprudencia del Tribunal de Justicia a través de cuatro litigios (Francovich, Factortame, Bosman y Kadi), un año de reseña jurisprudencial presenta dificultades de selección muy comprometidas. De julio de 2013 a junio de 2014 hay, no obstante, algunos aspectos que tienen una especial trascendencia y que incluso marcarán y se recordarán en el futuro: la primera cuestión prejudicial formulada por el Tribunal Constitucional alemán, las respuestas del Tribunal de Justicia anulando la Directiva sobre conservación de datos y proclamando el derecho al olvido en Internet, la aplicación en España del denominado «céntimo sanitario» contrariando las normas europeas de armonización fiscal y la nueva multa a España por no cumplir el régimen europeo de ayudas de Estado. 
En una primera parte doy cuenta de la cuestión prejudicial planteada por el Tribunal Constitucional Federal alemán (Bundesverfassungsgericht) en el asunto Gauweiler y otros (C-62/14) en la que se vuelve a suscitar el problema de la relación entre ordenamientos. Este acontecimiento jurídico coincide con la sentencia de amparo dictada por el Tribunal Constitucional español en el asunto Melloni, después de que se pronunciara el Tribunal de Justicia prejudicialmente y que ofrece, sin embargo, una división de comprensiones del Derecho de la Unión por los magistrados constitucionales españoles.

Una segunda parte se referirá a la jurisprudencia del Tribunal de Justicia sobre Internet y que, de manera fundamental, gira en torno a dos sentencias de gran calado interpretativo: la sentencia Digital Rights Ireland que anula la Directiva de conservación de datos y la sentencia Google Spain que ha tenido un eco global y supone anclar el derecho al olvido en la Directiva 95/46 y en la propia Carta de los Derechos Fundamentales de la Unión, en los derechos fundamentales a la vida privada y a la protección de los datos personales.

Y en una tercera parte, ya habitual en estas Crónicas, daré cuenta, por un lado, de algunas sentencias que el Tribunal de Justicia ha dictado en respuesta a los tribunales españoles que resultan de especial trascendencia, centrándome, básicamente, en la relativa al céntimo sanitario (sentencia Transportes Jordi Besora) y, por otro lado, en la significativa sentencia que de nuevo condena a España con una multa de 30 millones de euros por incumplir el régimen europeo de ayudas de Estado en relación con las denominadas «vacaciones fiscales vascas». También es preciso comentar las líneas abiertas por los jueces españoles a través de las nuevas cuestiones prejudiciales planteadas al Tribunal de Justicia.

\section{Los Tribunales Constitucionales también aplican el Derecho de la Unión (y plantean cuestiones prejudiciales)}

El Tribunal Constitucional Federal alemán ha acudido al Tribunal de Justicia formulando por vez primera en su historia una cuestión prejudicial después de que los tribunales ordinarios alemanes lo hiciesen profusamente (hasta 2013 habían planteado 2.050 cuestiones prejudiciales, muchas más que los jueces italianos, 1.227 reenvíos, o los franceses, solo en 886 ocasiones). Es cierto que numerosos tribunales constitucionales de otros Estados miembros ya había acudido reiteradamente a Luxemburgo. Coincidiendo en el tiempo el Tribunal Constitucional español, que se había atrevido a ir al Tribunal de Justicia antes que el alemán, resuelve por vez primera un recurso de amparo teniendo en cuenta la sentencia dictada por el Tribunal de 
Justicia en el asunto Melloni. Ahora bien, puede decirse que con el asunto Gauweiler y otros (C-62/14) el acceso de los Tribunales Constitucionales al Tribunal de Justicia se ha normalizado.

Ya venía siendo habitual que los Tribunales Constitucionales acudiesen a Luxemburgo (tal es el caso de la Cour constitutionnelle belga en 28 ocasiones, el Verfassungsgerichtshof austríaco en cinco supuestos, la Corte costituzionale italiana en dos ocasiones o el Conseil constitutionnel francés en un litigio); bien es verdad que quienes iniciaron este camino fueron los tribunales constitucionales de países medianos o pequeños, pero especialmente atrevidos y comprometidos con la integración europea. De hecho, en 2013 el Tribunal de Justicia tiene ocasión de responder al Tribunal Constitucional español en el asunto Melloni (Gran Sala, sentencia de 26 de febrero de 2013, C-399/11, ECLI:EU:C:2013:107) y al Consejo Constitucional francés en el asunto Jeremy $F$ (sentencia de 30 de mayo de 2013, C-168/13 PPU, ECLI:EU:C:2013:358) refiriéndose en ambos casos a la interpretación de la orden europea de entrega en el espacio europeo de libertad, seguridad y justicia.

El caso es que con el acceso normalizado de los Tribunales Constitucionales nacionales se sella una verdadera alianza de la jerarquía judicial que permite cuestionar al legislador nacional, que procura resolver de modo uniforme los conflictos entre los jueces ordinarios, y, en fin, que supera el miedo a colaborar entre los tribunales en Europa, cualquiera que sea su función y rango.

\section{El Bundesverfassungsgericht acude al Tribunal de Justicia: asunto Gauweiler y otros (C-62/14)}

A pesar de o precisamente por su actitud de desconfianza y crítica a la integración europea, el Tribunal Constitucional Federal alemán ha hecho notorias contribuciones a su consolidación: en la protección de los derechos fundamentales, proclamándose garante de los mismos mientras que (Solange) el Tribunal de Justicia asumiese su protección; en la consecución de una implicación de los parlamentos nacionales, con el fin de colmar el déficit democrático de la Unión; y, en fin, en su militante sensibilidad a los derechos fundamentales, incluido, por ejemplo, el derecho de autodeterminación informativa o de protección de los datos personales y de la privacidad.

Ante el Tribunal de Karlsruhe, Peter Gauweiler y otros (11.715 ciudadanos) formularon cuatro recursos de amparo al mismo tiempo que el Grupo Parlamentario del Bundestag alemán Die Linke (La Izquierda) planteaba un conflicto entre órganos constitucionales en relación con la validez y la interpretación de la Decisión, de 6 de septiembre de 2012, del Banco Central 
Europeo (BCE) sobre características técnicas de las operaciones monetarias de compraventa.

El Tribunal Constitucional Federal decidió plantear una cuestión prejudicial en su auto, de 14 de enero de 2014 (BVerfG, 2 BvR 2728/13, Absatz-Nr. (1-105), disponible también en inglés en http://www.bverfg.de/ entscheidungen/rs20140114_2bvr272813en.html ; último acceso 23/05/2014) donde, siguiendo la misma estrategia que el Tribunal Constitucional español en el asunto Melloni, plantea primero la cuestión de validez y, solo subsidiariamente, la cuestión de interpretación de la medida adoptada por el BCE para resolver el problema de la aplicación de tal normativa por el Bundesbank (Banco Central alemán).

En primer lugar, el Bundesverfassungsgericht plantea si la actuación del BCE es compatible y no desborda la regulación constitucional europea, es decir, si cumple los artículos 119 (política económica y monetaria) y 127 TFUE (política monetaria del Sistema Europeo de Bancos Centrales y del BCE) y los artículos 17 a 24 del Protocolo sobre los Estatutos del Sistema Europeo de Bancos Centrales y del Banco Central Europeo. En sustancia, el Tribunal Constitucional alemán quiere saber si es conforme con el Derecho originario de la Unión Europea el procedimiento establecido por el BCE de compra de deuda pública en la medida en que está condicionada por el Fondo Europeo de Estabilidad Financiera o al Mecanismo Europeo de Estabilidad, se refiere únicamente a determinados Estados miembros, etc., o precisamente por no establecer ningún límite cuantitativo a la compra de deuda pública, ni prever un intervalo temporal entre la emisión de deuda pública en el mercado primario y la compra de esta por parte del Sistema Europeo de Bancos Centrales (SEBC) en el mercado secundario, etc.

Y, de manera subsidiaria, el Tribunal alemán solicita al Tribunal de Justicia una interpretación del sistema monetario europeo y de la decisión del BCE con el fin de saber si el Eurosistema permite llevar a cabo las actuaciones previstas de compra de deuda pública.

Resulta patente que el Tribunal Constitucional Federal alemán no ve con buenos ojos la actuación del BCE en cuanto se refiere a sus decisiones sobre compra de deuda pública y a tal efecto explica que los recurrentes le piden al Tribunal alemán que «procure» la anulación de la decisión del BCE impugnada o que, al menos, impida su aplicación en cuanto se refiere al Bundesbank.

En sus razonamientos el Tribunal alemán se basa en su propia jurisprudencia sobre el Tratado de Maastricht, el Tratado de Lisboa y sobre la Unión Económica y Monetaria, así como en la jurisprudencia de otros Tribunales constitucionales de los Estados miembros (cita nueve decisiones de Tribunales Supremos o Constitucionales, incluida la Declaración de 13 de diciembre de 2004, DTC 1/2004, del Tribunal Constitucional español) en la 
medida en que pretenden «la protección de la identidad constitucional y establecen límites a la transferencia de poderes soberanos a la Unión Europea» (§§ 17 a 32$)$.

El Tribunal Constitucional alemán lleva a cabo su propia interpretación y sugiere claramente que la decisión del BCE supone una extralimitación en el ejercicio de las atribuciones constitucionales europeas al BCE. Asimismo, constituiría una violación de la prohibición constitucional contenida en el artículo 123 TFUE de prohibición de de financiación financiera del presupuesto mediante la adquisición de instrumentos de la deuda por el SEBC o el BCE.

No obstante, en sus razonamientos el Tribunal alemán se refiere a la sentencia Pringle del Tribunal de Justicia (Pleno, sentencia de 27 de noviembre de 2012, C-370/12, ECLI:EU:C:2012:756). De hecho, el Tribunal alemán considera que cabría una interpretación ajustada al Derecho de la Unión siempre que se cumpliese una serie de requisitos. En fin, el Tribunal alemán termina advirtiendo al Tribunal de Justicia que las competencias del Parlamento nacional alemán podrían verse comprometidas en la ejecución de la decisión del BCE por lo que podría suponer en caso de pérdidas para el Bundesbank y sus efectos en el presupuesto nacional.

Dos de los 8 jueces constitucionales, Gertrude Lübbe-Wolff y Michael Gerhardt, formularon sendos votos particulares contrarios a plantear la cuestión prejudicial en la medida en que los recursos ante el Tribunal Constitucional resultan inadmisibles y este sería incompetente para pronunciarse sobre los aspectos litigiosos.

En definitiva, el Tribunal Constitucional alemán expresa la desconfianza inoculada por el funcionamiento de la Eurozona, especialmente como Tribunal de uno de los países más sólidos económicamente. Sin embargo y al mismo tiempo, esta mano tendida al Tribunal de Justicia es un ensayo de cooperación que en un ámbito tan sensible como el del sistema monetario europeo y, en particular, de la Eurozona tiene una gran repercusión política y económica para los ciudadanos.

Probablemente con el auto de 14 de enero de 2014 planteando la cuestión prejudicial el Tribunal Constitucional alemán ha salvado esta primera etapa de desconfianza de los Tribunales Constitucionales respecto del Tribunal de Justicia y abre otra tan interesante como desafiante consistente en que el Tribunal de Justicia de la Unión Europea y cualesquiera otros Tribunales nacionales puedan acudir al Tribunal Europeo de Derechos Humanos. Como podremos ver a continuación, en la sentencia Digital Rights Ireland la colaboración entre el Tribunal Constitucional austriaco, así como el tribunal irlandés, contribuyen a depurar el ordenamiento europeo con la anulación por el Tribunal de Justicia de la Directiva sobre conservación de datos. 


\section{La actitud del Tribunal Constitucional español después de la sentencia Melloni}

La sentencia 26/2014, de 13 de febrero, del Pleno del Tribunal Constitucional español en el asunto Melloni (ponente: Roca Trías) es muy reveladora de la actitud de este tipo de tribunales hacia el Derecho de la Unión Europea por su recelo a perder la preeminencia y soberanía jurídica que ostentan en sus respectivos países. No obstante, los votos particulares formulados por las magistradas Adela Asua Batarrita y Encarnación Roca Trías, así como, por otras razones, el del magistrado Andrés Ollero Tassara, revelan la división de opiniones en el Tribunal Constitucional.

El recurso de amparo lo había interpuesto Stefano Melloni contra un auto de la Audiencia Nacional que en 2008 había acordado su entrega a Italia para cumplir el resto de la condena a diez años de prisión impuesta por los jueces italianos por delito de quiebra fraudulenta. En sus alegaciones el Sr. Melloni alegaba que se vulneraba el derecho constitucional a un proceso con todas las garantías al haber accedido la Audiencia Nacional a su entrega sin someterla a la condición de que pudiese impugnar la condena por un delito muy grave para salvaguardar sus derechos de defensa, tal como exigía la doctrina del Tribunal Constitucional español.

El Tribunal de Justicia contestó con su sentencia 26 de febrero de 2013 que ni la Decisión marco 2002/584/JAI relativa a la orden de detención europea, que establece un mecanismo de cooperación basado en la confianza recíproca de las autoridades nacionales, ni el artículo 53 de la Carta de los Derechos Fundamentales de la Unión, cuya interpretación no puede menoscabar la primacía del Derecho de la Unión, permiten que el Tribunal Constitucional español subordine la entrega de una persona condenada en rebeldía a la condición de que la condena pueda ser revisada en Italia para evitar una vulneración del derecho a un proceso con todas las garantías y de los derechos de la defensa protegidos por la Constitución española.

El Tribunal Constitucional cumple escrupulosamente la interpretación del Tribunal de Justicia. No obstante, existen discrepancias sobre los razonamientos y, en particular, sobre la fundamentación de la sentencia por remisión a la doctrina tradicional del Tribunal Constitucional.

En efecto, la sentencia refleja el sentir mayoritario que se inclina por establecer una especie de límites a la interpretación y aplicación del Derecho de la Unión Europea, basándose literalmente en la a DTC 1/2004, de 13 de diciembre. De todas las advertencias del Tribunal Constitucional español la que, sin duda, merece reproducirse es la relativa a una hipotética situación de involución en la Unión Europea que describe así: 
En el caso difícilmente concebible de que en la ulterior dinámica del Derecho de la Unión Europea llegase a resultar inconciliable este Derecho con la Constitución española, sin que los hipotéticos excesos del Derecho europeo respecto de la propia Constitución europea [léase hoy el propio Derecho Originario] fueran remediados por los ordinarios cauces previstos en ést[e], en última instancia la conservación de la soberanía del pueblo español y de la supremacía de la Constitución que éste se ha dado podrían llevar a este Tribunal a abordar los problemas que en tal caso se suscitaran, que desde la perspectiva actual se consideran inexistentes, a través de los procedimientos constitucionales pertinentes (FJ 3).

Aun presentando, al modo del Tribunal Constitucional alemán, este límite infranqueable para el Derecho de la Unión, el Tribunal español no duda en anunciar un giro jurisprudencial que supone literalmente la revisión «de la caracterización que este Tribunal ha venido realizando hasta ahora del denominado contenido absoluto del derecho a un proceso con todas las garantías» (art. 24.2 CE) (FJ 4). Sin embargo, para dar este paso el Tribunal Constitucional lo enmascara con un análisis de la jurisprudencia del Tribunal Europeo y del Tribunal de Justicia que lo llevan a esta conclusión:

Tanto la interpretación dada por el Tribunal Europeo de Derechos Humanos del derecho a un proceso equitativo recogido en el artículo 6 del Convenio europeo como la realizada por el Tribunal de Justicia de la Unión Europea de los derechos a la tutela judicial efectiva, a un proceso equitativo y de defensa recogidos en los arts. 47 y 48.2 de la Carta, coincidentes en buena medida, operan, en el caso que nos ocupa, como criterios hermenéuticos que nos permiten delimitar la parte de lo que hemos denominado contenido absoluto del derecho a un proceso con todas las garantías, que es la que despliega eficacia ad extra; esto es, la que permite delimitar aquellas facultades y garantías cuyo desconocimiento por las autoridades extranjeras puede dar lugar a una vulneración indirecta en caso de que acuerde la entrega por los poderes públicos españoles (FJ 4).

En suma, el Tribunal español acata la sentencia Melloni dictada en Luxemburgo pero, no obstante, recuerda los límites del Derecho a la Unión y reformula su jurisprudencia acudiendo no tanto a la sentencia Melloni que él mismo había provocado como a la jurisprudencia tanto del Tribunal de Justicia como del Tribunal Europeo de Estrasburgo.

Por eso llevan razón los votos particulares que, por una parte, en el caso de Asua Batarrita muestra su discrepancia con la sentencia en «su fundamentación jurídica, tanto por lo que dice y hace como por lo que no dice». En primer lugar, la magistrada discrepante insiste en que «la Sentencia de la mayoría desaprovecha la ocasión de reflexionar y reflejar las importantes transformaciones que la pertenencia a la Unión Europea ocasiona a nues- 
tra función jurisdiccional y a los procesos constitucionales por medio de los cuales se realiza la preeminencia de la Constitución». Asimismo, critica que se siga utilizando más bien el artículo 10.2 de la Constitución y no el artículo 93 para fundamentar la aplicación de los derechos fundamentales de la Unión. Sobre este particular, la magistrada discrepante explica:

El canon que debemos aplicar ex art. $93 \mathrm{CE}$ en razón de nuestra pertenencia a la Unión Europea: estando plenamente armonizada la regulación de la ejecución de las órdenes europeas de detención y entrega, lo que hay que aplicar son única y exclusivamente los derechos fundamentales de la Unión, en este caso los derechos fundamentales reconocidos en los arts. 47 y 48 de la Carta tal y como han sido específicamente interpretados, a instancia nuestra, por el Tribunal de Justicia en la Sentencia de 26 de febrero de 2013.

En fin, el voto particular termina con una contundente observación: «La idea de que esta jurisdicción no aplica derechos de la Unión sino los derechos fundamentales de la Constitución española, si bien convenientemente interpretados de manera que coincidan indefectiblemente con el nivel de protección reconocido en la Unión, no deja de ser una ficción poco convincente».

Del mismo modo, en su voto particular, la magistrada Roca Trías, incomprensiblemente la propia ponente de la sentencia mayoritaria, explica su discrepancia: «el Pleno, si bien cumple con el estándar europeo, deja abiertas a la ambigüedad cuestiones verdaderamente importantes que no favorecen la lógica de la Unión que, no olvidemos, encuentra su sustento en los principios de la lealtad y cooperación leal, primacía y subsidiariedad del derecho de la Unión en el ámbito de sus competencias y respeto por la identidad constitucional recíproca». Por último, la magistrada Roca Trías resume sus argumentos contrarios a la sentencia de la mayoría porque no especifica cuáles son los motivos por los que se accede al cambio de los cánones hasta ahora utilizados en nuestro sistema que conforman la interpretación del derecho a la defensa, no se alude a la naturaleza del Derecho de la Unión respecto a los derechos y deberes contenidos en la Carta, no se incluyen criterios o cánones constitucionales que deban regir en las extradiciones a países terceros y, en definitiva, el Tribunal Constitucional no asume su papel de Juez europeo.

El tercer voto particular, del magistrado Ollero Tassara, es de signo muy distinto y resulta calculadamente ambiguo pues por una parte anuncia lo que podría entenderse como una vía de rebeldía nacionalista: «No me parece que la mejor manera de inaugurar lo que se vislumbra como un laborioso «diálogo de Tribunales» entre el Constitucional español y el de Justicia de la Unión Europea, sea prestarle innecesariamente aire de monólogo con obligado asentimiento». También el magistrado discrepante lanza un aviso en estos términos: «la situación planteada debiera haber animado a 
nuestro Tribunal a recordar la conveniencia de que la Unión Europea suscriba a su vez el Tratado de Roma, para evitar que sus Estados miembros se vean obligados en incómodo escorzo a un innecesario diálogo a tres, a la hora de fijar los obligados contenidos mínimos en la protección de los derechos humanos». Pero, por otra parte y en este caso de modo técnicamente intachable, advierte: «No veo razón alguna para la que el trato excepcional que del artículo $93 \mathrm{CE}$ deriva haya de hacerse extensivo a la inmensa mayoría de países ajenos a la Unión Europea».

Sea como fuere, las reticencias o resquemores, en parte al menos superados por nuestro Tribunal Constitucional, revelan una evidencia que ya ponía de manifiesto el juez norteamericano Jackson que en su famoso voto particular a una sentencia de 1954 señalaba que la infalibilidad del Tribunal Supremo de Washington se debía únicamente a que eran los últimos en pronunciarse y que, sin ir tan lejos, nuestro refranero populariza con el conocido «quien ríe el último ríe mejor».

\section{La nueva Jurisprudencia Europea sobre internet: sentencias Digital Rights Ireland, Google Spain y otras}

La jurisprudencia europea sobre Internet ha llegado a su máxima expresión en dos sentencias tan significativas como Digital Rights Ireland y Google Spain. Pero también el Tribunal de Justicia ha seguido pronunciándose sobre los litigios vinculados al desarrollo de Internet y ha abordado cuestiones cada vez más interesante para la sociedad digital.

Esta jurisprudencia permite observar un fenómeno creciente en la jurisprudencia de nuestros días de una iusfundamentalización, lo que significa una tendencia a reducir los litigios a un problema del alcance del derecho a la protección de datos personales en Internet, tal como se consagra en la Carta de los Derechos Fundamentales y a sus efectos tanto en lo que se refiere a la validez como a la interpretación del Derecho de la Unión, cuestionando incluso la validez de la misma legislación vigente, en relación con otros derechos fundamentales, de manera especial la privacidad y la libertad de expresión.

1. La anulación de la Directiva sobre conservación de datos: la sentencia Digital Rights Ireland

La High Court de Dublín y el Tribunal Constitucional austriaco se atrevieron a cuestionar la validez de la Directiva 2006/24/CE sobre la conservación de datos generados o tratados en relación con la prestación de servi- 
cios de comunicaciones electrónicas de acceso público o de redes públicas de comunicaciones y el Tribunal de Justicia en su sentencia Digital Rights Ireland anuló esta Directiva básicamente porque era contraria a los artículos 7 (derecho a la vida privada) y 8 (derecho a la protección de los datos personales) de la Carta de los Derechos Fundamentales de la Unión.

La Directiva sobre conservación de datos personales se había adoptado en 2006 como consecuencia del temor provocado por las acciones terroristas en Estados Unidos en 2001, en Madrid en 2004 y en Londres en 2005 y suponía, sin lugar a dudas, un recorte de derechos aunque su finalidad era la protección en el ámbito penal.

Siguiendo un razonamiento muy similar al que utiliza en Estrasburgo el Tribunal Europeo, el Tribunal de la Unión constató en su sentencia Digital Rights Ireland, en primer lugar, que había una injerencia de esta Directiva tanto en el derecho a la vida privada como en el derecho fundamental a la protección de los datos personales. Seguidamente, el Tribunal de Justicia observó que tal injerencia estaba justificada, entre otras razones, por la necesidad de luchar contra el terrorismo internacional. Sin embargo, al aplicar el test de proporcionalidad el Tribunal de Justicia llegó a la conclusión de que la regulación contenida en la Directiva excedía los límites del Derecho de la Unión.

En este sentido, el Tribunal de Justicia advirtió que el alcance de la injerencia era muy amplio y revestía una especial gravedad sin que se hubiesen establecido limitaciones a los proveedores de servicios ni se hubiesen adoptado medidas de control de los datos por una autoridad independiente ni respecto de países terceros de la Unión.

Lo más relevante de esta sentencia no solo es la anulación de la Directiva sino la fuerza con que al unísono actúan el derecho de privacidad y el derecho de protección de datos personales que requerirán una pronta rectificación del legislador europeo habida cuenta que la Directiva en cuestión se había incorporado a las legislaciones nacionales que, como es obvio y ya sin el amparo de la Directiva, están condenadas a su anulación en la medida en que no hayan superado los reparos establecidos por el Tribunal de Justicia.

\section{El derecho al olvido como manifestación de la Directiva 95/46: sentencia Google Spain}

El último hito histórico de la jurisprudencia del Tribunal de Justicia es la sentencia Google Spain que tiene su origen en la cuestión prejudicial planteada por la Audiencia Nacional al Tribunal de Justicia sobre el alcance del derecho al olvido.

La cuestión prejudicial fue planteada desde España en una impugnación que la conocida empresa Google y su filial Google Spain habían enta- 
blado contra una resolución de la Agencia Española de Protección de Datos que amparaba en parte la denuncia de don Mario Costeja González. El litigio se centraba en saber si la empresa californiana Google o su filial en España están obligadas a borrar de Internet todos los datos referidos a un embargo previo de bienes seguido lícitamente contra un ciudadano, publicados en 1998 en La Vanguardia de Barcelona y que se recuperaban fácilmente a través de una consulta en el motor de búsqueda en la medida en que tal información referida a la vida privada de un ciudadano particular ya no tenía razón de ser tantos años después en que había rehecho su vida y superado una etapa crítica.

A la vista de las numerosas preguntas del tribunal español, el abogado general abordó, básicamente, tres cuestiones que revelan los problemas generales creados por la protección de los derechos fundamentales vulnerados a través de Internet: la aplicación territorial del derecho a la protección de datos personales, la aplicación objetiva de la Directiva de 1995 a los buscadores en Internet, a Google, y el contenido del derecho al olvido. Precisamente sobre el derecho al olvido, el abogado general sostuvo que no podría ejercitarse frente a Google porque no se recogía expresamente en la Directiva 95/46 (apartado 137).

En cambio, el Tribunal de Justicia llega en la sentencia Google Spain a una conclusión mucho más atrevida: no duda de la aplicación de la Directiva 95/46 a Internet y a los buscadores, deduce responsabilidades de los gestores de motores de búsqueda, independientemente de la responsabilidad de los editores de las páginas de Internet, y reconoce que de los derechos de privacidad y de protección de los datos personales, consagrados en la Carta de los Derechos Fundamentales de la Unión, deriva un derecho de los ciudadanos a solicitar que la información que ofrecen los buscadores de Internet ya no se ponga a disposición del público en general mediante su inclusión en una lista de resultados (apartado 97); solución que puede ser distinta, según los casos y en particular si se trata de la actividad del editor de la página web (apartado 86).

De hecho y como evidencia de la tendencia a la iusfundamentalización de los litigios se puede observar que la sentencia Google Spain fue, por lo general, bien acogida en Europa subrayándose la importancia para la privacidad y la protección de los datos personales. Sin embargo, la reacción desde los Estados Unidos fue mayoritariamente de preocupación no solo por el futuro de una de sus multinacionales sino, a juicio de los estadounidenses, por el peligro que esta restricción podría tener para la libertad de expresión. Ahora bien, la sentencia Google Spain exigirá, primero, la adopción de las propuestas legislativas adoptadas por la Comisión Europea en 2012, y, después, requerirá un examen caso por caso y una ponderación de los derechos fundamentales en juego. 


\section{Otras sentencias sobre Internet: competencia judicial y lucha contra la ciberpiratería}

En el periodo examinado el Tribunal de Justicia ha pronunciado también numerosas sentencias relativas a los efectos de Internet en nuestras vidas y que tratan, resumidamente, de dos cuestiones básicas: la competencia judicial y la protección de los derechos de autor.

Por lo que se refiere al juez competente cuando la lesión de los derechos se produce a través de Internet las sentencias Pinckney y Emrek se completan con la respuesta dada también en la sentencia Google Spain.

En la sentencia Pinckney el Tribunal de Justicia responde a la Cour de cassation francesa que le había planteado la cuestión relativa a la competencia judicial en el caso de un compositor, residente en Francia, que demandaba ante los tribunales franceses a una empresa austriaca que había fabricado discos compactos vulnerando sus derechos de autor; estos discos fueron comercializados en Internet por dos empresas británicas. El Tribunal de Justicia se apoyó en la jurisprudencia anterior y distinguió, a fin de identificar el lugar de la materialización de un daño supuestamente causado en Internet, entre las vulneraciones de los derechos de la personalidad y las vulneraciones de un derecho de la propiedad intelectual o industrial, permitiendo optar entre distintos tribunales del lugar donde se haya materializado el daño (apartados 31 a 34). En el caso de los daños patrimoniales de autor, dada la posibilidad de obtener en un sitio de Internet accesible desde cualquier lugar una reproducción de la obra a la que están vinculados los derechos, serían competentes los jueces de los distintos Estados miembros pero únicamente para conocer del daño causado en el territorio del Estado miembro al que pertenezcan.

En la sentencia Emrek el Tribunal de Justicia zanja la discusión sobre la competencia de los jueces alemanes para conocer de una demanda del Sr. Emrek, domiciliado en Alemania, y que había comprado un vehículo de ocasión en Francia. Los hechos se produjeron en una zona (Spicheren y Saarbrücken) donde existe una continuidad urbana ajena a la línea fronteriza entre los dos países; y en la página web del vendedor se facilitaba un teléfono móvil con prefijo de Alemania.

El Tribunal de Justicia llegó a la conclusión de que, si bien para determinar en este caso la competencia de los jueces alemanes, no se exigiría que existiese una relación causal entre el medio utilizado para dirigir la actividad comercial o profesional a Alemania, donde tiene su domicilio el consumidor, a saber, una página web, y la celebración del contrato con dicho consumidor; no obstante, la existencia de tal relación causal constituye un indicio de vinculación del contrato a tal actividad.

En fin, la sentencia Google Spain completa la anterior jurisprudencia para el caso de las filiales de los gigantes tecnológicos, como era el caso de 
la filial española de Google, poniendo de manifiesto la vinculación entre la filial y la matriz y haciéndolas responsables ante las autoridades administrativas y judiciales españolas, es decir, sometiéndola a la Directiva 95/46.

En lo que se refiere a los derechos de autor, la piratería en Internet es una fuente de preocupaciones y el origen de numerosos litigios que han llegado al Tribunal de Justicia, como es el caso de las sentencias Innoweb, Svensson, UPC Telekabel Wien y BEST.

En la sentencia Innoweb el Tribunal de Justicia examinó, a petición del tribunal neerlandés, la cuestión de la reutilización de otras bases de datos en los términos que regula la Directiva 96/9/CE sobre la protección jurídica de las bases de datos, en este caso a través de un metamotor de búsqueda dedicado, es decir, el que «utiliza los motores de búsqueda de otros sitios de Internet transfiriendo las órdenes de búsqueda de sus usuarios a otros motores de búsqueda, característica que lo distingue de motores de búsqueda generales como Google».

El Tribunal de Justicia consideró que mediante este procedimiento se estaba reutilizando una base de datos y en particular la persona que explota un metamotor de búsqueda dedicado «puede hacer perder dinero al fabricante de la base de datos, en particular el obtenido a través de la publicidad realizada en su sitio de Internet, privándolo de ese modo de ingresos que se supone deberían permitirle amortizar el coste de su inversión en la constitución y el funcionamiento de la base de datos» (apartado 41).

En la sentencia Svensson el Tribunal de Justicia contesta a un tribunal sueco de apelación la solución al litigio planteado por un periodista en defensa de sus derechos de autor sobre artículos publicados en un periódico abierto al público. Desde otra página web se remitía mediante un enlace directamente a estos artículos por parte de una persona distinta del periodista y titular del derecho de propiedad intelectual.

Ahora bien, a juicio del Tribunal de Justicia al hacer clic desde otra página web y acceder a los artículos lo que en realidad está haciendo es una comunicación al público de esa obra en el sentido de la Directiva 2001/29/CE. Y en este caso «el hecho de facilitar en una página de Internet enlaces sobre los que se puede pulsar y que conducen a obras protegidas publicadas sin ninguna restricción de acceso en otra página de Internet ofrece a los usuarios de la primera página un acceso directo a dichas obras» (apartado 18). Continúa el Tribunal de Justicia subrayando que «dado que no existe un público nuevo, no es necesario que los titulares de los derechos de autor autoricen una comunicación al público como la del litigio principal» (apartado 28).

En la sentencia UPC Telekabel Wien el Tribunal de Justicia le aclaró al Tribunal Supremo austriaco si una persona que, sin el consentimiento del titular del derecho, ponía a disposición del público en Internet una prestación 
protegida estaba recurriendo a los servicios de los proveedores de acceso a Internet y si era compatible con el Derecho de la Unión prohibir a un proveedor de acceso de forma general que facilitase a sus clientes el acceso a un determinado sitio de Internet mientras en él se ponían a disposición del público exclusiva o predominantemente contenidos sin el consentimiento del titular del derecho.

El Tribunal de Justicia en su sentencia parece aceptar las restricciones de los Derecho nacionales aunque puntualiza, en primer lugar, que «un proveedor de acceso a Internet (que) permite a su clientes acceder a prestaciones protegidas puestas a disposición del público en Internet por un tercero, es un intermediario a cuyos servicios se recurre para infringir derechos de autor o derechos afines a los de autor en el sentido del artículo 8, apartado 3, de la Directiva 2001/29» (apartado 32). Y seguidamente el Tribunal europeo matizó su respuesta en estos términos:

Los derechos fundamentales reconocidos por el Derecho de la Unión deben interpretarse en el sentido de que no se oponen a que, mediante un requerimiento emitido por un juez, se prohíba a un proveedor de acceso a Internet conceder a sus clientes acceso a un sitio de Internet que ofrece en línea prestaciones protegidas sin el consentimiento de los titulares de los derechos, cuando dicho requerimiento no especifica qué medidas debe adoptar ese proveedor de acceso y éste puede eludir las sanciones derivadas del incumplimiento de dicho requerimiento demostrando que adoptó todas las medidas razonables, con la condición, no obstante, de que, por una parte, las medidas adoptadas no priven inútilmente a los usuarios de Internet de la posibilidad de acceder de forma lícita a la información disponible, y, por otra parte, dichas medidas tengan como efecto impedir o, al menos, hacer difícilmente realizable el acceso no autorizado a las prestaciones protegidas y disuadir seriamente a los usuarios de Internet que recurran a los servicios del destinatario de dicho requerimiento de consultar esas prestaciones puestas a su disposición en violación del derecho de propiedad intelectual, extremo que corresponde verificar a las autoridades y a los órganos jurisdiccionales nacionales (apartado 64).

En la sentencia BEST el Tribunal de Justicia resolvió una cuestión prejudicial planteada por el Tribunal Supremo belga en relación con el registro y utilización de un nombre de dominio y el uso de metadatos de un sitio de Internet. La sentencia analizó si en el concepto de publicidad debían incluirse el registro, la utilización de un nombre de dominio y la utilización de indicadores de hipertexto en los metadatos de un sitio de Internet.

En cuanto se refiere al registro de un nombre de dominio, el Tribunal de Justicia consideró que no se incluía en el concepto de publicidad. En cambio, el uso de un nombre de dominio y la utilización de los indicadores de 
hipertexto (metadatos o palabras clave) se incluyen en el concepto de publicidad.

En definitiva, el Tribunal de Justicia seguirá conociendo, a través de las cuestiones prejudiciales, distintos aspectos de la lucha contra la piratería y la protección de los derechos de autor y de los derechos de marcas en Internet que afinarán los límites que impone el Derecho de la Unión a los Derechos nacionales buscando el difícil equilibrio en la ponderación de los intereses en juego.

\section{Los efectos de la Jurisprudencia Europea en el Derecho Español: Las sentencias sobre el «céntimo sanitario» y la nueva multa por no recuperar ayudas ilegales}

Además de seguir planteando nuevas cuestiones prejudiciales, los tribunales españoles reciben numerosas respuestas del Tribunal de Justicia donde frecuentemente se pone de manifiesto la escasa fortuna del legislador español, sean las Cortes Generales sean los Parlamentos autonómicos, a la hora de aplicar el Derecho de la Unión: la sentencia Transportes Jordi Besora sobre el denominado céntimo sanitario es un ejemplo significativo de esta preocupante situación.

Asimismo, después de tantos años de integración en la Unión Europea sorprende que las autoridades españolas, incluidas las autonómicas y locales, sigan sin comprender y ajustarse al régimen de las ayudas de Estado que, entre otras cosas, exige la recuperación de las ayudas ilegales e incompatibles como dolorosamente había advertido el Tribunal de Justicia en el caso $M a-$ gefesa y que condenó a España al pago de una multa, una suma a tanto alzado por importe de 20 millones (Gran Sala, sentencia de 11 de diciembre de 2012, Comisión / España, C-610/10, ECLI:EU:C:2012:78), cuando ahora lo ha vuelto a recordar el Tribunal de Justicia pero afeando nuevamente la conducta de las autoridades españolas e imponiéndoles una multa de $30 \mathrm{mi}$ llones de euros por no recuperar las ayudas declaradas ilegales por la Comisión Europea.

\section{La sentencia Transportes Jordi Besora (céntimo sanitario)}

Probablemente la decisión de más trascendencia económica dictada por el Tribunal de Justicia en el periodo de esta Crónica sea la sentencia Transportes Jordi Besora, una empresa de transportes que reclamaba ante el Tribunal Superior de Justicia de Cataluña la devolución del Impuesto sobre las Ventas Minoristas de Determinados Hidrocarburos (IVMDH), denominado 
«céntimo sanitario», que se aplicó por casi todas las Comunidades Autónomas desde 2002.

Las distintas cuestiones planteadas por el Tribunal catalán las reduce el Tribunal de Justicia a saber si este impuesto autonómico de venta minorista de hidrocarburos era conforme a la Directiva 92/12 sobre impuestos especiales.

El Tribunal de Justicia recuerda que si bien los hidrocarburos pueden estar sujetos a impuestos indirectos distintos del impuesto especial previsto en la Directiva 92/12 deben cumplir dos requisitos que tienen carácter cumulativo: por una parte, deben perseguir una o varias finalidades específicas, y, por otra parte, deben respetar las normas impositivas aplicables en relación con los impuestos especiales o con el IVA para la determinación de la base imponible, la liquidación, el devengo y el control del impuesto (apartado 21).

Respecto del primer requisito, que cumplan una finalidad específica, el Tribunal de Justicia subraya que es objetivo distinto del exclusivamente presupuestario. A la hora de analizar el impuesto autonómico español el Tribunal de Justicia constata que «el tipo de gravamen de dicho impuesto es el resultado de la suma del tipo de gravamen fijado a escala estatal y del tipo de gravamen fijado por la Comunidad Autónoma de que se trate». Asimismo, el Tribunal de Justicia comprueba que, si bien «la afectación predeterminada de los rendimientos de un impuesto como el IVMDH a la financiación por parte de autoridades regionales, como las Comunidades Autónomas, de competencias que les ha transferido el Estado en materia de sanidad y medioambiente podría constituir un elemento que debe tenerse en cuenta para identificar la existencia de una finalidad específica», tal afectación, que resulta de una mera modalidad de organización presupuestaria interna de un Estado miembro, no puede, como tal, constituir un requisito suficiente a este respecto, ya que cualquier Estado miembro puede ordenar la afectación del rendimiento de un impuesto a la financiación de determinados gastos, sea cual sea la finalidad perseguida» (apartados 28 y 29).

Sin embargo y a juicio del Tribunal de Justicia este impuesto perseguiría una finalidad específica si se acreditase que pretende garantizar la protección de la salud y del medioambiente.

Por lo que se refiere a los gastos sanitarios, aun cuando las Comunidades Autónomas deben afectar los rendimientos del IVMDH a los gastos sanitarios en general, y no a los vinculados específicamente al consumo de los hidrocarburos gravados, tales gastos generales pueden financiarse mediante el rendimiento de toda clase de impuestos (apartado 31).

Por cuanto se refiere a la protección del medioambiente, la legislación española no establece ningún mecanismo de afectación predeterminada a fines medioambientales de los rendimientos del IVMDH ni su estructura, en 
particular el hecho imponible o el tipo de gravamen, está concebida de tal modo que disuada a los contribuyentes de utilizar los hidrocarburos o que fomente el uso de otros productos menos nocivos para el medio ambiente (apartado 32).

Constatada la incompatibilidad del impuesto autonómico sobre el céntimo sanitario, la abogada del Estado intentó, sin éxito, reducir el efecto presupuestario de esta interpretación. En efecto, el Tribunal de Justicia denegó la posibilidad de limitar los efectos temporales retroactivos de esta sentencia porque no se cumplían los presupuestos: no había habido buena fe de las autoridades españolas dado que en el año 2000 el Tribunal de Justicia se había pronunciado en un supuesto similar y las consecuencias financieras que podrían derivarse para un Estado miembro de una sentencia dictada con carácter prejudicial no justifican, por sí solas, la limitación en el tiempo de los efectos de esa sentencia.

\section{Las respuestas a otras cuestiones prejudiciales españolas}

De las demás respuestas a cuestiones prejudiciales «españolas» solo dedicaré un comentario breve a algunas sentencias y autos dictados en Luxemburgo.

La sentencia Betriu Montull responde una cuestión planteada por el Juzgado de lo Social n. ${ }^{\circ} 1$ de Lleida con el fin de saber si la prestación por maternidad podía ser disfrutada por el padre; previamente el Tribunal Constitucional había considerado que la legislación española de la seguridad social no era contraria al artículo 14 de la Constitución, pero el Juzgado catalán planteó si la regulación española era contraria al Derecho de la Unión Europea.

El Tribunal de Justicia, sin desautorizar al Tribunal Constitucional, llegó a la conclusión de que «las Directivas 92/85 y 76/207 deben interpretarse en el sentido de que no se oponen a una medida nacional como la controvertida en el litigio principal, que dispone que el padre de un menor, que tiene la condición de trabajador por cuenta ajena, puede, con el consentimiento de la madre, que tiene también la condición de trabajadora por cuenta ajena, tener derecho a un permiso de maternidad para el período posterior a las seis semanas de descanso obligatorio para la madre inmediatamente posteriores al parto, salvo en el caso de que exista un riesgo para la salud de ésta, mientras que el padre de un menor, que tiene la condición de trabajador por cuenta ajena, no puede tener derecho a tal permiso cuando la madre de su hijo no tiene la condición de trabajadora por cuenta ajena y no está afiliada a un régimen público de seguridad social» (apartado 72). Aclara el Tribunal de Justicia que conforme al Derecho aplicable a los he- 
chos enjuiciados «ni el Tratado CE, ni ninguna Directiva de la Unión, ni ninguna otra disposición del Derecho de la Unión prohibían las discriminaciones entre padres adoptivos y padres biológicos por lo que respecta al permiso de maternidad».

La sentencia Márquez Samohano tiene su origen en un litigio de un profesor asociado con la Universitat Pompeu Fabra ante un Juzgado de lo Social de Barcelona que pretendía saber si el Derecho de la Unión se oponía a la renovación por las universidades públicas de sucesivos contratos de duración determinada celebrados con profesores asociados, sin límite alguno en lo que atañe a la duración máxima y al número de renovaciones de dichos contratos.

La respuesta del Tribunal de Justicia, siguiendo su jurisprudencia anterior, se centra en interpretar las garantías establecidas a favor de los trabajadores con contratos de duración determinada.

En primer lugar, el Tribunal de Justicia considera que un profesor asociado de una universidad, cuyo contrato de trabajo, según el Derecho español, debe celebrarse necesariamente por una duración determinada, está incluido en el ámbito de aplicación del Acuerdo marco.

En segundo lugar, el Tribunal de Justicia recuerda que la finalidad de la legislación europea es «imponer límites a la utilización sucesiva de contratos o relaciones laborales de duración determinada, considerada fuente potencial de abusos en perjuicio de los trabajadores, estableciendo un cierto número de disposiciones protectoras mínimas con objeto de evitar la precarización de la situación de los asalariados» (apartado 41). Por eso, se impone «a los Estados miembros, a efectos de prevenir los abusos como consecuencia de la utilización sucesiva de contratos o relaciones laborales de duración determinada, la adopción efectiva y vinculante de una o varias de las medidas que enumera cuando su Derecho interno no contemple medidas legales equivalentes». Estas medidas se refieren, respectivamente, a las razones objetivas que justifiquen la renovación de tales contratos o relaciones laborales, a la duración máxima total de los sucesivos contratos de trabajo o relaciones laborales de duración determinada y al número de sus renovaciones (apartado 42).

Por último y en el caso concreto de los profesores asociados de universidad, el Tribunal de Justicia reconoce que los estatutos de la universidad no incluyen ninguna medida legal equivalente, pero también comprueba los distintos tipos de profesor asociado. Y por eso responde, matizadamente, que la renovación de estos contratos de trabajo puede estar justificada por una razón objetiva, en los términos de su propia jurisprudencia. De modo que los verdaderos profesores asociados, profesionales de prestigio que desarrollan su labor fuera de la universidad, pueden estar sometidos a un régimen de renovación sucesiva; en cambio, «la renovación de contratos o re- 
laciones laborales de duración determinada para atender a necesidades que en realidad no tienen carácter temporal, sino muy al contrario permanente y duradero, no está justificada» por el Derecho de la Unión.

La sentencia Iberdrola Distribución Eléctrica se dicta en respuesta a la cuestión prejudicial del Tribunal Superior de Justicia valenciano que debía interpretar la Directiva 85/337/CEE relativa a la evaluación de las repercusiones de determinados proyectos públicos y privados sobre el medio ambiente en relación con un proyecto concreto de ampliación de una subestación transformadora de tensión eléctrica. El Tribunal de Justicia le explica que, si bien la mera ampliación de una subestación transformadora de tensión eléctrica no figura, en cuanto tal, entre los proyectos de la Directiva, la obligación de evaluación de impacto ambiental tiene un ámbito de aplicación extenso y un objetivo amplio. A tal efecto, el Tribunal de Justicia subraya que la Directiva contempla una apreciación global del impacto de los proyectos sobre el medio ambiente.

El Juzgado de lo Social de Terrassa cuestionó en Luxemburgo la conformidad de la ley española de tasas judiciales con la Carta de Derechos Fundamentales de la Unión. Sin embargo, el Tribunal de Justicia en su sentencia Torralbo Marcos inadmitió el reenvío prejudicial al considerar, básicamente, que el litigio planteado ante el juez catalán no estaba comprendido dentro del ámbito de aplicación del Derecho de la Unión. En particular, el Tribunal de Justicia constata que la normativa española relativa a las tasas en el ámbito de la administración de justicia no tiene por objeto aplicar disposiciones del Derecho de la Unión y tampoco el Derecho europeo contiene normativa específica en la materia o que pueda afectar a la normativa nacional. Ni siquiera el hecho de que el demandante pretendiese obtener una declaración de insolvencia del empresario para beneficiarse de la intervención del Fogasa de conformidad con la Directiva 2008/94 es suficiente, a juicio del Tribunal de Justicia, para considerar que la situación de que se trata estaba comprendida dentro del ámbito de aplicación de dicha Directiva y, por consiguiente, del Derecho de la Unión.

La trascendencia de esta decisión radica en la delimitación que hace el Tribunal de Justicia del ámbito de aplicación de la Carta en la medida en que «las disposiciones de la Carta se dirigen a los Estados miembros únicamente cuando apliquen el Derecho de la Unión» y «los derechos fundamentales garantizados en el ordenamiento jurídico de la Unión deben ser aplicados en todas las situaciones reguladas por el Derecho de la Unión, pero no fuera de ellas».

Por último, es preciso reseñar que el Tribunal de Justicia archivó una cuestión prejudicial de un tribunal español, en este caso el Juzgado de lo Mercantil de Pontevedra (asunto Acosta Padín, C-276/13), que se refería al ejercicio de la profesión de procurador y al cobro mediante arancel. Por se- 
gunda vez (la primera fue en el asunto también archivado Fradera Torredemer y otros, C-364/12) llegaba esta espinosa cuestión a Luxemburgo y, sin embargo, las partes en el procedimiento judicial español decidieron solucionarlo extrajudicialmente. Es un problema que se repite y que, por el momento, parece que no interesa que se resuelva convenientemente a la luz del Derecho de la Unión.

\section{La sentencia de multa por las vacaciones fiscales vascas (C-184/11)}

Si la multa de 20 millones de euros impuesta a España en 2012 por el incumplimiento de la sentencia que condenaba a España por no recuperar las ayudas ilegales e incompatibles concedidas a finales de los años 80 a Magefesa y a sus empresas sucesoras no sirvió de escarmiento o quizás las autoridades españolas la consideraron módica, el Tribunal de Justicia no ha tenido ninguna prevención en imponer un multa de 30 millones de euros por el incumplimiento de la obligación de recuperar las ayudas ilegales conocidas como vacaciones fiscales vascas.

En 2001 la Comisión Europea adoptó seis decisiones por las que declaraba que determinadas ventajas fiscales, consistentes en un crédito fiscal del $45 \%$ de las inversiones y aplicable al impuesto sobre sociedades, otorgadas por las tres diputaciones forales vascas eran ayudas ilegales e incompatibles con el mercado común y debían ser recuperadas por las autoridades españolas. Por sentencia del Tribunal de Justicia de 14 de diciembre de 2006 se declaró que España había incumplido su obligación de recuperación de tales ayudas.

Por tanto, la Comisión Europea inició un procedimiento de ejecución forzosa de la sentencia declarativa de incumplimiento proponiendo al Tribunal de Justicia que impusiese a España una multa coercitiva por importe de 236.044,80 euros por cada día de retraso en la ejecución de la sentencia que dictase forzando a la ejecución y una suma a tanto alzado cuyo importe resultase de multiplicar una cantidad diaria de 25.817,40 euros por el número de días de persistencia de la infracción transcurridos desde la fecha en que se dictó la sentencia de 2006 hasta esta sentencia de 2014. Finalmente, el Tribunal de Justicia solo accedió a imponer una suma a tanto alzado de 30 millones de euros.

Por una parte, el Tribunal de Justicia consta el incumplimiento de las sentencias y de las Decisiones de la Comisión Europea de recuperación de la totalidad de las ayudas ilegales. El Tribunal de Justicia distingue dos modos de comprobar el cumplimiento de la devolución del importe de las ayudas en los términos señalados en un procedimiento de ejecución forzosa de una sentencia: antes de la entrada en vigor del Tratado de Lisboa, 
se toma como referencia el plazo señalado en el dictamen motivado emitido; y después del Tratado de Lisboa, al haberse suprimido la fase de emisión de un dictamen motivado, se tiene en cuenta el plazo fijado en el escrito de requerimiento, en este caso la fecha de referencia era el 27 de agosto de 2008. El Tribunal de Justicia apenas atiende a razones y considera que en esa fecha «las autoridades españolas no habían recuperado en su integridad las ayudas ilegales de que se trata que debían ser objeto de restitución» (apartado 38).

En segundo lugar y por lo que se refiere a la imposición de la suma a tanto alzado, el Tribunal de Justicia argumenta, por un lado y respecto de la implicación de las administraciones forales, que «el reparto de competencias entre el poder central y el poder regional en el ámbito interno no afecta a la aplicación del artículo 260 TFUE, en la medida en que el Estado miembro de que se trate es el único responsable, frente a la Unión Europea, del cumplimiento de las obligaciones que resultan del Derecho de la Unión» (apartado 43).

Y, por otro lado, se pronuncia sobre la procedencia de imponer a España una suma a tanto alzado de más de 64 millones de euros que solicitaba la Comisión con el fin de prevenir de manera efectiva «que en el futuro se repitan infracciones análogas del Derecho de la Unión» por lo que pretendía «la adopción de una medida disuasoria, como la condena al pago de una suma a tanto alzado».

El Tribunal de Justicia subraya que le corresponde determinar las sanciones apropiadas, es decir, tiene «una amplia facultad de apreciación para decidir si procede o no imponer una sanción de este tipo y, en caso afirmativo, la cuantía de ésta» (apartado 60). Y para ello el Tribunal de Justicia tiene en cuenta la duración del incumplimiento, es decir, más de cinco años después de la sentencia declarativa del incumplimiento. Asimismo, constata que solo dos años después de dictarse la sentencia las autoridades españolas «comenzaron a someter detalladamente a dicha institución los problemas con los que se habían encontrado» (apartado 67).

En segundo lugar y por lo que se refiere a la gravedad de la infracción, el Tribunal de Justicia recuerda «el carácter fundamental de las disposiciones del Tratado CE en materia de ayudas de Estado» (apartado 69); asimismo, se refiere a la importancia que tiene la devolución de las ayudas de Estado declaradas ilegales e incompatibles con el mercado interior para eliminar la distorsión de la competencia causada por la ventaja competitiva proporcionada por ellas y pretende, con la devolución, que el beneficiario pierda la ventaja de la que había disfrutado ilegalmente en el mercado respecto a sus competidores (apartado 71). De hecho, el Tribunal de Justicia comprobó que cuando se dictó la sentencia declarativa por incumplimiento debían recuperarse más de 179 millones y en la fecha de interposición del 
recurso de ejecución forzosa eran 91 millones de euros, es decir una cuantía elevada.

Y, por último, el Tribunal de Justicia señala que España ya había sido condenada reiteradamente "por no haber recuperado de una manera inmediata y efectiva ayudas declaradas ilegales e incompatibles con el mercado interior» (apartado 75), refiriéndose expresamente a las sentencias Comisión/España, C-499/99, EU:C:2002:408; Comisión/España, C-404/00, EU:C:2003:373; Comisión/España, C-177/06, EU:C:2007:538, y Comisión/España, C-529/09, EU:C:2013:31 y la sentencia Comisión/España, EU:C:2012:781. Sobre este particular el Tribunal de Justicia señala: «tal repetición de comportamientos ilícitos de un Estado miembro, en un sector específico de la acción de la Unión, puede constituir un indicador de que para prevenir efectivamente la repetición en el futuro de infracciones análogas del Derecho de la Unión es preciso adoptar una medida disuasoria, como la condena al pago de una suma a tanto alzado» (apartado 78).

Finalmente y remitiendo a los razonamientos anteriores el Tribunal de Justicia fija equitativamente, dice que después de «una justa apreciación de las circunstancias del caso», la suma a tanto alzado en 30 millones de euros (apartado 83).

Esta preocupante enfermedad que ya parece endémica requería la adopción del Real Decreto 515/2013, de 5 de julio, por el que se regulan los criterios y el procedimiento para determinar y repercutir las responsabilidades por incumplimiento del Derecho de la Unión Europea $(B O E$ n. ${ }^{\circ} 161$, de 6 de julio de 2013). De hecho, este procedimiento parece pensado de manera especial para resolver los problemas planteados en materia de ayudas de Estado.

Esta regulación se apresura a subrayar en su preámbulo: «el procedimiento aquí regulado no tiene naturaleza sancionadora, sino que se limita a derivar responsabilidades y para ello se establecen los criterios y procedimiento a seguir para determinar y repercutir las mencionadas responsabilidades».

Esto le permite al Gobierno de la Nación expresar un concepto de sanción que resulta particularmente amplio y aplicable, por tanto, en el régimen de ayudas de Estado a los supuestos de sentencias de ejecución forzosa adoptadas para obtener la devolución de ayudas ilegales e incompatibles. En efecto, el artículo 3.2 del Real Decreto 515/2013 dispone:

Tendrá la consideración de sanción para el Reino de España la imposición, mediante sentencia, acto o decisión ejecutiva de las instituciones europeas, de una multa a tanto alzado o una multa coercitiva, de conformidad con lo dispuesto en el artículo 260 del Tratado sobre el Funcionamiento de la Unión Europea, las correcciones financieras adoptadas me- 
diante decisión de la Comisión Europea, la minoración de las cuantías de las transferencias o fondos que a España le puedan corresponder del presupuesto de la Unión Europea o cualquier otro acto adoptado por una institución, órgano u organismo de la Unión Europea que implique responsabilidades financieras para el Estado o la merma de cualquier cantidad que le hubiera sido reconocida.

Subsidiariamente y para no dejar ningún cabo suelto, también en materia de ayudas de Estado, cualquier responsabilidad podría ventilarse entre el Estado y las Comunidades Autónomas y demás organismos a los que se aplica el Real Decreto 515/2013 cuando su artículo 3.3.e) establece:

Se entenderá que existe un incumplimiento cuando se realicen actuaciones u omisiones contrarias al Derecho de la Unión Europea y en particular, entre otros, en los siguientes supuestos: e) Falta de ejecución o ejecución incorrecta de sentencias, actos o decisiones dictados por las instituciones europeas.

El reparto de las responsabilidades internas debe hacerse atendiendo tanto al Derecho de la Unión como al Derecho español. Sobre este particular, el Real Decreto 515/2013 es consciente de la importancia que tienen los actos de las instituciones de la Unión al señalar en su art. 5.1.2, «para la determinación de la correspondiente responsabilidad se atenderá a las sentencias, actos o decisiones ejecutivas de las instituciones europeas que declaren el incumplimiento, y se ponderará en cada caso, entre otros, los criterios de competencia, intensidad de la intervención, participación en la financiación asignada y la reiteración».

En efecto, la determinación de las responsabilidades para hacer frente a las multas coercitivas y a las sumas a tanto alzado en sentencias de ejecución forzosa en materia de ayudas vendrá bastante mediatizada por la labor previa de constatación de la responsabilidad de España que se haya ventilado ante el Tribunal de Justicia.

\section{Las nuevas cuestiones prejudiciales españolas}

De las nuevas cuestiones prejudiciales planteadas por los jueces españoles a Luxemburgo merecen destacarse, por su contenido, cinco: una referida a la aplicación de la Directiva que prohíbe la discriminación por razón de la edad (Vital Pérez); otra que tiene que ver con los límites del Derecho de la Unión a la expulsión administrativa de extranjeros (Zaizoune); dos relativas al régimen de ayudas de Estado (Elcogás y Navantia); y, en fin, una en la que será interesante saber si un órgano administrativo como un tribunal 
de contratos públicos puede plantear una cuestión prejudicial (Consorci Sanitari del Maresme).

El Juzgado de lo Contencioso-administrativo n. ${ }^{\circ} 4$ de Oviedo planteó al Tribunal de Justicia una cuestión prejudicial (Vital Pérez, C-416/13) sobre la conformidad de la ley asturiana, que, como otras leyes autonómicas, establecía el límite para el acceso a las plazas de agente de la policía local en 30 años, con la Directiva que prohíbe la discriminación por razón de la edad.

La cuestión prejudicial planteada, por el Tribunal Superior de Justicia del País Vasco en el asunto Zaizoune (C-38/14) se suscita en un asunto en el que un nacional marroquí residente en San Sebastián recurría contra su expulsión con la prohibición de entrada en cinco años por estar indocumentado y con antecedentes penales por tráfico de drogas (más de dos años de prisión). El Juzgado de lo Contencioso-administrativo de San Sebastián había anulado la expulsión pero el Tribunal vasco decide preguntarle al Tribunal de Justicia si la Directiva 2008/115/CE se opone a la legislación y jurisprudencia españolas que permiten sancionar la situación irregular de un extranjero exclusivamente con una sanción económica que, además, resulta incompatible con la sanción de expulsión.

En materia de ayudas de Estado, tanto el Tribunal Supremo como un Juzgado han preguntado si una determinada actuación es o no ayuda de Estado, especialmente en el ámbito fiscal.

La petición de decisión prejudicial presentada por la Sala de lo Contencioso-administrativo del Tribunal Supremo en el asunto Elcogás, S.A. / Administración del Estado e Iberdrola, S.A. (C-275/13) pretende saber si son ayuda de Estado las cantidades anuales asignadas a la sociedad Elcogás en cuanto titular de una instalación singular de generación de energía eléctrica, tal como se prevé en los planes de viabilidad extraordinarios aprobados por el Gobierno español en el marco de los denominados «costes permanentes del sistema eléctrico» (véase el interesantísimo auto de planteamiento del Tribunal Supremo (Sala C-A, Sección 3. a, auto de 22 de abril de 2013, recurso n. ${ }^{\circ}$ 181/2011, ponente: Campos Sánchez-Bordona).

El Juzgado Contencioso-Administrativo n. ${ }^{\circ} 1$ de Ferrol conoce del asunto que enfrenta al Ministerio de Defensa y Navantia, empresa pública de construcción naval, con el Concello de Ferrol (C-522/13) y le pregunta al Tribunal de Justicia de si la exención fiscal sobre el Impuesto de Bienes Inmuebles de la que se beneficia la empresa pública es compatible con el régimen de ayudas de Estado.

Por último, es preciso reseñar que el Tribunal catalán de contratos públicos (Tribunal Català de Contractes del Sector Públic) ha planteado una cuestión prejudicial en el asunto Consorci Sanitari del Maresme (C-203/14). Será interesante saber si el Tribunal de Justicia, del mismo modo que ocurrió con el Tribunal Económico-administrativo y con el Tribu- 
nal de Defensa de la Competencia, órganos administrativos de conformidad con el Derecho español, considera órganos jurisdiccionales a los efectos del reenvío prejudicial a estos nuevos tribunales administrativos especializados en contratación pública.

\section{Relación de las sentencias comentadas del Tribunal de Justicia de la Unión Europea}

1. TJ (Sala 4. ${ }^{\mathrm{a}}$ ) sentencia, de 19 de septiembre de 2013, Marc Betriu Montull / Instituto Nacional de la Seguridad Social (C-5/12, ECLI:EU:C:2013:571) (permiso de maternidad y derechos del cónyuge).

2. TJ (Sala 3. ${ }^{\text {a }}$, sentencia de 11 de julio de 2013, Belgian Electronic Sorting Technology NV (C-657/11, ECLI:EU:C:2013:516) (registro y utilización de un nombre de dominio y metadatos de un sitio de Internet).

3. TJ, auto de 11 de septiembre de 2013, Acosta Padín (C-276/13, ECLI:EU:C:2013:586) (intervención de procurador y aranceles).

4. TJ (Sala 4. ${ }^{\mathrm{a}}$ ), sentencia de 3 de octubre de 2013, Peter Pinckney / KDG Mediatech AG (C-170/12, ECLI:EU:C:2013:635) (competencia judicial y vulneración de derechos de autor en Internet).

5. TJ (Sala 3. ${ }^{\mathrm{a}}$ ), sentencia de 17 de octubre de 2013, Emrek (C-218/12, ECLI:EU:C:2013:666) (competencia judicial y actividad comercial a través de Internet).

6. TJ (Sala 5. ${ }^{\text {a)}}$, sentencia de 19 de diciembre de 2013, Innoweb BV contra Wegener ICT Media BV y Wegener Mediaventions BV (C-202/12, ECLI:EU:C:2013:850) (metamotor de búsqueda dedicado y aprovechamiento de otras bases de datos).

7. TJ (Sala 4. ${ }^{\mathrm{a}}$ ), sentencia de 13 de febrero de 2014, Nils Svensson y otros / Retriever Sverige AB (C-466/12, ECLI:EU:C:2014:76) (remisión de una página web a otra con artículos periodísticos accesibles a todos).

8. TJ (Sala 2. ${ }^{\text {a) }}$, sentencia de 27 de febrero de 2014, Transportes Jordi Besora SL / Generalitat de Catalunya (C-82/12, ECLI:EU:C:2014:108).

9. TJ (Sala 8. ${ }^{a}$ ), sentencia de 13 de marzo de 2014, Antonio Márquez Samohano / Universitat Pompeu Fabra (C-190/13, ECLI:EU: C:2014:146) (contratación de profesores asociados de Universidad y los límites de la Directiva sobre contratos de duración determinada).

10. TJ (Sala 7. a), sentencia de 27 de marzo de 2014, Ayuntamiento de Benferri / Consejería de Infraestructuras y Transporte de la Genera- 
litat Valenciana e Iberdrola Distribución Eléctrica SAU (C-300/13, ECLI:EU:C:2014:188) (Directiva de evaluación de impacto ambiental y proyectos).

11. TJ (Sala 2. ${ }^{\mathrm{a}}$ ), sentencia de 27 de marzo de 2014, Emiliano Torralbo Marcos / Korota SA y Fondo de Garantía Salarial (C-265/13, ECLI:EU:C:2014:187) (incompetencia del Tribunal de Justicia y tasas judiciales).

12. TJ (Sala 4. ${ }^{\mathrm{a}}$ ), sentencia de 27 de marzo de 2014, UPC Telekabel Wien (C-314/12, ECLI:EU:C:2014:192) (medidas cautelares judiciales contra intermediarios en la lucha contra los ciberpiratas).

13. TJ (Gran Sala), sentencia de 8 de abril de 2014, Digital Rights Ireland (C-293/12 y C-594/12, ECLI:EU:C:2014:238) (anulación de la Directiva sobre conservación de datos en materia penal).

14. TJ (Gran Sala), sentencia de 13 de mayo de 2014, Google Spain y Google Inc. / Agencia Española de Protección de Datos (AEPD), Mario Costeja González (C-131/12, ECLI:EU:C:2014:317) (motores de búsqueda y derecho al olvido en Internet).

15. TJ (Gran Sala), sentencia de 13 de mayo de 2014, Comisión / España (C-184/11, ECLI:EU:C:2014:316) (régimen de ayudas y multa por no recuperar las ayudas de las «vacaciones fiscales vascas»). 